\title{
Profile of Biermer's Disease at the Medical Clinic II Abass Ndao Hospital Center: About 57 Colliged Cases
}

\author{
Michel Assane Ndour1* ${ }^{*}$ Djiby Sow ${ }^{1}$, Demba Diedhiou${ }^{1}$, Boundia Djiba1, Ibrahima Mané Diallo1, \\ Alassane Baro', Jeanne Anna Bentaux ${ }^{1}$, Muriel Diembou ${ }^{1}$, Marie Louise Bassene ${ }^{2}$, \\ Maimouna Ndour Mbaye ${ }^{1}$, Fatou Samba Diago Ndiaye ${ }^{3}$, Anna Sarr ${ }^{1}$ \\ ${ }^{1}$ Department of Internal Medicine, Abass Ndao Hospital Center, Dakar, Senegal \\ ${ }^{2}$ Department of Gastroenterology, Aristide Le Dantec Hospital Center, Dakar, Senegal \\ ${ }^{3}$ Department of Hematology, Dalal Djam Hospital Center, Dakar, Senegal \\ Email: *michelassanendour@yahoo.fr
}

How to cite this paper: Ndour, M.A., Sow, D., Diedhiou, D., Djiba, B., Diallo, I.M., Baro, A., Bentaux, J.A., Diembou, M., Bassene, M.L., Mbaye, M.N., Ndiaye, F.S.D. and Sarr, A. (2020) Profile of Biermer's Disease at the Medical Clinic II Abass Ndao Hospital Center: About 57 Colliged Cases. Open Journal of Internal Medicine, 10, 141-150.

https://doi.org/10.4236/ojim.2020.102015

Received: March 21, 2020

Accepted: May 8, 2020

Published: May 11, 2020

Copyright $\odot 2020$ by author(s) and Scientific Research Publishing Inc. This work is licensed under the Creative Commons Attribution International License (CC BY 4.0).

http://creativecommons.org/licenses/by/4.0/ (c) (i) Open Access

\begin{abstract}
Introduction: Biermer's disease is an autoimmune cause of anemia characterized by malabsorption of vitamin B12. It is often accompanied by other autoimmune pathologies. The objective was to study its profile in patients followed in the internal medicine department of the Abass Ndao hospital center. Methods: This was a retrospective and descriptive study of patients followed for Biermer's disease from January 1, 2014 to December 31, 2019 (5 years). Results: 57 cases were collected, an incidence of 5.4 in the internal medicine department. The sex ratio was 0.58 , an average age of 56.4 years. The circumstances of discovery were dominated by anemic syndrome $(87.7 \%)$, dermatological (33.3\%), digestive (29.8\%), neurological (20\%) pathologies. The specific signs to Biermer's disease were digestive manifestations in $70.2 \%$ (including 30\% Hunter's glossitis), neurological manifestations in $36.8 \%$ (including $17.5 \%$ paresthesias), palmoplantar melanoderma in $68.4 \%$. The mean hemoglobin level was $6.8 \mathrm{~g} / \mathrm{dL}$ with a mean corpuscular volume of $110.7 \mathrm{fl}$. The myelogram reported megaloblastosis in $100 \%$ of the cases. The mean serum vitamin B12 level was $100 \mathrm{pg} / \mathrm{ml}$. The anti-intrinsic factor antibody assay performed in 50 patients was positive in all cases. Upper digestive endoscopy showed an aspect of fundic atrophy in 69\%. Histology showed intestinal metaplasia in 2 patients. An autoimmune disease was associated in $21 \%$ of cases. All patients had received treatment with vitamin B12 (51 patients took intramuscularly and 6 oral treatment). The course was favorable in all cases with a complete correction of the anemia. Conclusion: Biermer's disease is a reality in Senegal. Its clinical and biological characteristics can be superim-
\end{abstract}


posed on the data in the literature. His prognosis under treatment is good whatever the route of administration of vitamin B12.

\section{Keywords}

Biermer, Autoimmune Disease, Vitamin B12, Dakar

\section{Introduction}

Biermer's disease (formerly known as pernicious anemia) is an autoimmune atrophic gastritis, predominantly fundic, responsible for a malabsorption of vitamin B12. It is characterized immunologically by the presence of anti-intrinsic factor antibodies and/or anti-parietal cells antibodies. Its prevalence is $0.1 \%$ in the general population and $1.9 \%$ in subjects over 60 years of age. It accounts for $50 \%$ of the etiologies of vitamin B12 deficiency in adults [1]. It most often manifests as a neuro-anemic syndrome associated with digestive signs, notably Hunter's glossitis and melanoderma. It is often associated with other autoimmune disorders (vitiligo, dysthyroidism, autoimmune adrenal insufficiency, Sjögren syndrome) [2] [3]. Its treatment is based on the administration of vitamin B12 for life by the parenteral route [1] or oral [4]. Biermer's disease remains insufficiently described in Senegal. In Senegal, an old retrospective study carried out in 2008 focused on this pathology but did not assess the impact of oral treatment. The objective of this study will be therefore to study the clinical epidemiological profiles but also the associated comorbidities and the course of treatment in patients followed at the Abass Ndao Hospital Center.

\section{Patients and Methods}

This was a retrospective, descriptive study of the cases of Biermer's disease collected over a period of 05 years (from January 1, 2014 to December 31, 2019). We included in the study any patient for whom the diagnosis of Biermer's disease was confirmed. Apart from clinical manifestations, the confirmation of Biermer's disease in our series was carried out on a bundle of arguments. These were: the existence of a macrocytic type anemia (mean corpuscular volume $>$ $100 \mathrm{fl}$ ) and/or a decrease in serum vitamin B12 levels (vitamin B12 less than 130 $\mathrm{ng} / \mathrm{l}$ ) and/or megaloblastosis in the medullogram and/or a positivity of intrinsic anti-factor antibodies and/or the presence of endoscopic or histological signs of atrophic gastritis. Incomplete records (hemogram, serum vitamin B12, anti-intrinsic factor antibody, esogastroduodenal fibroscopy, medullogram) were not included. The data were collected on a pre-established survey sheet and were also collected from patient medical records. The parameters necessary for the study were:

- Socio-demographic data: age, sex, existence of an associated autoimmune disease; 
- Clinical data: circumstance of discovery, anemic syndrome, digestive, dermatological, neuropsychic signs.

We also took into account the biological data: hemogram, myelogram, serum folic acid, plasma ferritin, serum vitamin B12, antibodies against intrinsic factor, antibodies against parietal cells. The reference values were $130-800 \mathrm{ng} / \mathrm{l}$ for vitamin B12, 150 - $450 \mathrm{ug} / \mathrm{l}$ for folic acid, $18-160 \mathrm{ng} / \mathrm{l}$ in men and $7-160 \mathrm{ng} / \mathrm{l}$ in women for ferritin. The results of upper gastrointestinal endoscopy as well as those of histology were also collected. Apart from the full clinical examination, an exploration of associated pathologies, especially autoimmune, was made either directly (specific antibodies in the event of signs of orientation) or indirectly by the determination of calcemia, glycemia, TSH us, cortisol, protidemia.

Therapeutically, the dosage and method of administration of vitamin B12 were noted. It consisted of the administration of vitamin B12 in the form of hydroxycobalamin.

Two protocols have been established:

- Intramuscularly: $1000 \mu \mathrm{g}$ per day for one week, then $1000 \mu \mathrm{g}$ per week for one month, then $1000 \mu \mathrm{g}$ once per month for life;

- Orally: $2000 \mu \mathrm{g}$ per day for one week then $2000 \mu \mathrm{g}$ per week for one month; then $2000 \mu \mathrm{g}$ per os once a month for life.

The adjuvant treatments were an iso-group iso-rhesus blood transfusion in case of poorly tolerated anemia, iron supplementation for iron deficiency, eradicator treatment for Helicobacter pylori.

The evolution under treatment was evaluated on the erythrocyte response after 7 days of treatment (the erythrocyte crisis was retained on an increase in the reticulocyte level greater than 10 times normal), on the correction of anemia over 3 months, the state of neurological, gastric manifestations and death.

The results were captured and analyzed using an electronic questionnaire developed with SPSS 24.0 software. This software was used to calculate frequencies, averages and standard deviations.

\section{Results}

\subsection{Epidemiological Data}

We included 57 patients among 1044 patients followed in internal medicine (consultation and hospitalization) during the study period, an incidence of $5.46 \%$. These were 21 men and 36 women, for a sex ratio of 0.58 . The average age of the patients was $54.6 \pm 13$ years (extremes of 27 and 80 years). It was on average 53 years for women and 59.2 years for men (Table 1). The most represented age group for women was 40 - 60 years old (61.1\%) and that of men over 60 years old (47.6\%). Figure 1 shows the distribution of age groups by gender.

\subsection{Clinical Data}

The average delay of consultation was 15 months. The reasons for consultation were dominated by symptoms of anemia in $87.7 \%$, followed by dermatological 
Table 1. Epidemiological profile of patients by gender.

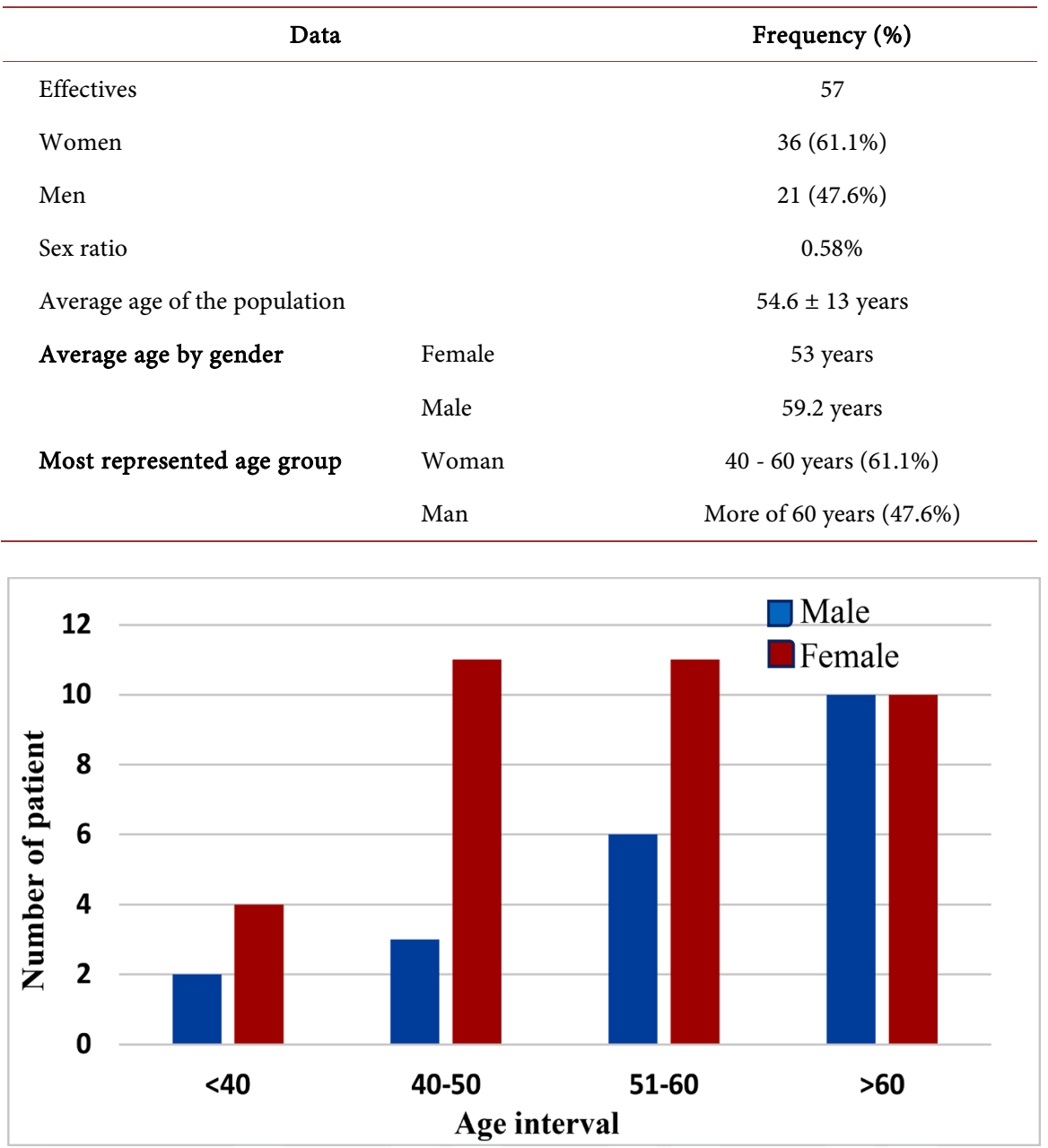

Figure 1. Distribution of age groups by gender.

(33.3\%), digestive (29.8\%) and neurological (20\%) manifestations.

In terms of the signs specific to Biermer's disease, palmoplantar melanoderma was noted in 39 patients (68.4\%) (Figure 2). Anemic syndrome was found in 50 patients $(87.7 \%$ including pallor in $82.5 \%$, jaundice in $26.3 \%$ and anorganic systolic murmur in 14\%). Anemic syndrome was poorly tolerated in 35 patients (61.4\%) who required a blood transfusion. Digestive signs were present in 44 patients $(70.2 \%)$ dominated by Hunter's glossitis (29.8\%) (Figure 3) and chronic epigastralgia (25\%). Neurological signs were present in 21 patients $(36.8 \%$ including limb paresthesia in all cases, combined sclerosis syndrome in 10.5\%). Table 2 summarizes the clinical signs found in our patients.

\subsection{Paraclinical Data}

The hemogram found anemia in $93 \%$ of patients $(n=53)$. The average hemoglobin level was $6.8 \mathrm{~g} / \mathrm{dl}$ (extremes of 1.8 and 15). It was less than $5 \mathrm{~g} / \mathrm{dl}$ in $33.3 \%$ and between 5 and $8 \mathrm{~g} / \mathrm{dl}$ in $24.6 \%$. The mean corpuscular volume (MCV) was $110 \mathrm{fl}$ (extremes of 90 and 140). Anemia was predominantly macrocytic in $77 \%$, 

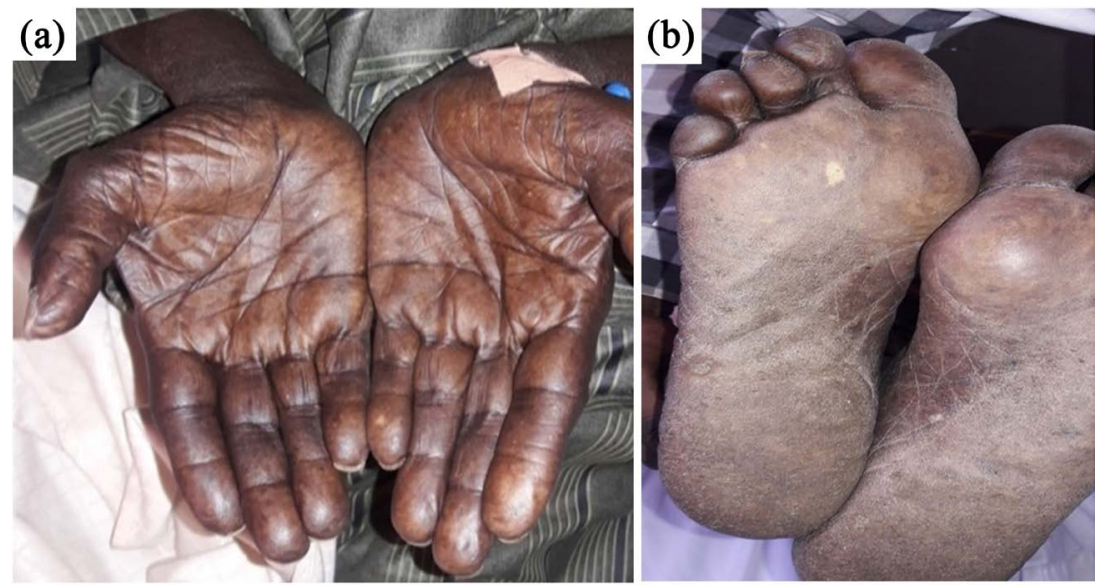

Figure 2. Palmo (a) plantar (b) melanoderma related to Biermer's disease.

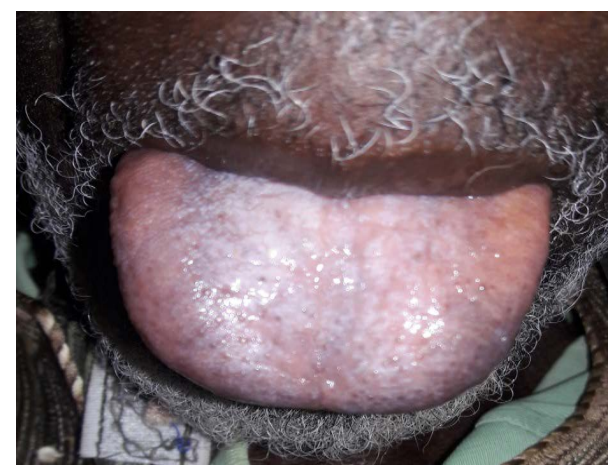

Figure 3. Hunter's glossitis (Abass Ndao Medical Clinic).

Table 2. Clinical characteristics of patients.

\begin{tabular}{llcc}
\hline Clinical signs & & Effectives & Percentage \\
\hline Anemic syndrome & Skin and mucous pallor & 47 & $82.4 \%$ \\
& Anorganic systolic breath & 8 & $14 \%$ \\
& Tachycardia & 53 & $93 \%$ \\
& Dyspnea exertional & 35 & $61.4 \%$ \\
Digestive manifestations & Hunter glossitis & 17 & $29.8 \%$ \\
& Transit disorders & 17 & $29.8 \%$ \\
& Epigastralgia & 12 & $21 \%$ \\
Neurological manifestations & Combined spinal sclerosis & 6 & $10.5 \%$ \\
& Sensitive neuropathy & 5 & $8.8 \%$ \\
& Isolated paraesthesia & 10 & $17.5 \%$ \\
Dermatological signs & Palmoplantar melanoderma & 39 & $68.4 \%$ \\
\hline
\end{tabular}

normocytic in $23 \%$. Bi-cytopenia was noted in 23 patients or $40 \%$ of cases and pancytopenia in 17 patients or $30 \%$ of patients. The dosage of serum vitamin B12 was done in 48 patients or $85.7 \%$. Vitamin B12 deficiency was noted in all patients with an average serum level of $100 \mathrm{pg} / \mathrm{ml}$ (extremes of 23 and 156). Iron 
deficiency (low serum ferritin levels) was associated in $14 \%$ of the cases. Anti-intrinsic factor antibodies were produced in 40 patients (71.4\%). They were positive in all cases. Functional renal failure was found in 30 cases (52.6\%).

The myelogram, performed in 35 patients, found megaloblastosis in all patients. Esogastroduodenal fibroscopy (F.O.G.D.) was performed in 52 patients (91\%). It was associated with a biopsy in 11 patients or $11 \%$. It showed atrophic gastritis in $69 \%$ of patients $(\mathrm{n}=34)$, intestinal metaplasia in 2 patients $(3.5 \%)$. Helicobacter Pylori was found in $3.5 \%$ of cases $(n=2)$.

\subsection{Therapeutic Data}

Treatment with vitamin B12 was prescribed in all patients. The intramuscular route was used in 41 patients and the oral route in 16 patients. Blood transfusion was required in 35 patients (61.4\%). Eight patients with associated iron deficiency received iron supplementation and 3 patients received Helicobacter pylori eradication therapy. Normalization of hemoglobin level was observed in all patients after an average of 03 months of treatment. The course was marked by a reticulocytic crisis on the 8th day of treatment in all patients.

\subsection{Associated Pathologies}

Organ-specific autoimmune disease was associated in 12 patients (21\% including $7 \%$ autoimmune dysthyroidism, $3.5 \%$ type 1 diabetes, $5.3 \%$ vitiligo damage and $1.7 \%$ systemic lupus).

\section{Discussion}

It was a retrospective, descriptive study of the profile of Biermer's disease. It presented limits because the paraclinical explorations, often necessary for the diagnosis, were not always accessible. The exploration prices were on average 87,000 fcfa for vitamin B12 + antibodies against intrinsic factors, 12,000 fcfa for the medullogram and 30,000 fcfa for digestive endoscopy. As a result, many patients did not carry out all of the necessary investigations.

\subsection{Epidemiological Data}

The female prevalence and the average age noted in our series were superimposable on the data of the literature [5] [6] and comparable to the gender profile of autoimmune diseases. Biermer's disease is described as rare before 30 years of age, with a frequency which then increases, reaching a peak around 60 years of age [7]. The average delay of consultation was 15 months. This long delay is partly linked to the chronic and asymptomatic nature of the disease.

\subsection{Clinical Data}

Anemia is almost constant during Biermer's disease and is the main manifestation reported in Sub-Saharan Africa [5] [6]. In the series by Ndiaye et al. [6], the revealing manifestations were dominated by anemia in $100 \%$ of the cases, fol- 
lowed by epigastralgia (61.5\%), glossitis (23.1\%), transit disorders (15.3\%). Neurological (53\%) and dermatological (42.3\%) manifestations were also reported. In our series, Hunter's glossitis was the most suggestive sign of the disease. Regarding the neurological manifestations, there were mainly paresthesias of the lower limbs (17.5\% of cases). According to the literature, this peripheral sensory neuropathy is quite frequent and constitutes the first neurological manifestation of Biermer's disease [8]. Furthermore, the combined degeneration of the spinal cord remains the classic neurological picture during this disease. According to Ndiaye et al. [6], it represents $20 \%$ to $30 \%$ of Biermer's diseases with neurological presentation. We found $10 \%$ of combined sclerosis of the spinal cord. Palmoplantar melanoderma found in $68.4 \%$ of our patients remains less described in the literature. It is more frequent in black subjects than in leukoderms [6]. The study by Ndiaye et al. [6] reported $42.3 \%$ of cases.

\subsection{Paraclinical Data}

On the biological level, the anemia found in $93 \%$, remains frequently reported [7] [8] [9]. However, Biermer's disease can present without anemia [6]. In the series of Lindenbaum et al. [10] and Federici et al. [3], the hemoglobin level was normal in $24 \%$ and $28 \%$ respectively. Analysis of hematimetric constants noted macrocytosis more frequently (77\%). Conventionally, Biermer's disease manifests with macrocytosis [6] [7] [11]. However, the mean corpuscular volume can also be normal in the case of Biermer's disease even in the absence of associated pathology [12]. Achlorydria can be the essential determinant through an associated iron deficiency. Besides anemia, leukopenia or thrombocytopenia are sometimes seen during this disease. In the Maktouf et al. [13] cohort, $48 \%$ of cases had thrombocytopenia. In the literature, several authors have reported cases of pancytopenia [3] [6] [13] [14]. Besides the medullary richness, the existence of megaloblasts, observed in $100 \%$ of our subjects, was constantly reported by the literature [3] [6] [8]. The positivity of anti-intrinsic factor antibodies remains specific at $98 \%$. These antibodies can however be found in 2 to $5 \%$ of healthy subjects, as well as in 1st grade parents of an affected subject. [15]. However, the absence of anti-intrinsic factor antibodies and anti-parietal cell gastric antibodies does not rule out this diagnosis, since these immunological abnormalities are absent in approximately $30 \%$ of cases during authentic Biermer disease [16].

Histologically, the rate of atrophic gastritis found at $69 \%$ agrees with the literature [6] [14]. It is an almost constant diagnostic criterion reported with a high frequency in the majority of published studies. However, Biermer anemia can be observed outside of any gastric atrophy [5] [6]. A triggering role for Helicobacter pylori in the autoimmune process has been suggested [17].

\subsection{Therapeutic Data}

The parenteral route remains the preference in all African series [9] [12] [14]. However, recent studies have opened several perspectives by suggesting the in- 
terest of the oral route or even the nasal route [4] [18]. There is no consensus on the dosage and timing of vitamin B12 during Biermer's disease. The same is true for the use of oral vitamin therapy. Many comparative therapeutic trials have confirmed the efficacy of vitamin B12 administered orally, in particular with the studies of Troilo et al. [19] and Kaltenbach et al. [20]. In fact, the first team to evaluate the effectiveness of vitamin B12 by the oral route, in Biermer's disease and para biermerian, noted a significant increase in the serum concentration of vitamin B12 on average by $161.6 \pm 79 \mathrm{pg} / \mathrm{ml}$ in the maldigestion group ( $\mathrm{p}<$ $0.00005)$ and $136.7 \pm 67.4 \mathrm{pg} / \mathrm{ml}$ in the group of patients with Biermer's disease $(\mathrm{p}<0.0001)$ [20]. Symptomatic treatment was mainly iso-rhesus iso-group blood transfusion in $61.4 \%$. This rate was almost similar to that of Wun Chan et al. [8] which reported $76 \%$.

The evolution marked by an improvement in the anemic syndrome and neurological signs was matching with the data in the literature [21] [22]. In the Andrès et al. [23] series, the average hemoglobin level increased from 6.2 to 12.4 $\mathrm{g} / \mathrm{l}$ and the mean corpuscular volume from 103.5 to $91.2 \mathrm{fl}$ in 4 months.

In our study, we observed an association with other autoimmune diseases in 12 patients. In the Tunisian studies of Maktouf et al. [8] and Achat et al. [24], it was found that mainly autoimmune thyropathies are in $23.4 \%$ and $57 \%$ respectively.

\section{Conclusion}

In Biermer's disease, the majority profile of the elderly female subject remains demonstrated. There is a clinical polymorphism dominated by anemia, Hunter's glossitis. The macrocytic profile dominates, however some chronic cases were revealed by normocytosis. The positive immunological assessment in our patients confirms our diagnoses. Upper gastrointestinal endoscopy remains crucial in the identification of atrophic gastritis. Because of its autoimmune nature, a systematic search for another associated autoimmune pathology is required. Therapeutically, all our patients have benefited from lifelong B12 vitamin therapy mainly via the intramuscular route. At the end of this study, it would be important to evoke Biermer's disease before any macrocytosis, even isolated, in order to reduce the diagnostic delay, to use the alternative route to injectable treatment which is also effective, to make additional examinations accessible including immunological examinations for early diagnosis.

\section{Conflicts of Interest}

The authors declare no conflicts of interest regarding the publication of this paper.

\section{References}

[1] Zulfiqar, A.A., Serraj, K., Pennaforte, J.L. and Andrès, E. (2012) Maladie de Biermer: De la physiopathologie à la clinique. Médecine thérapeutique, 18, 21-29. 
[2] Baker, S.J. (1979) Hyperpigmentation and Pernicious Anemia in Blacks. Archives of Internal Medicine, 139, 1316-1316. https://doi.org/10.1001/archinte.1979.03630480088028

[3] Federici, L., Henoun, L.N., Zimmer, J., Affenberger, S., Maloisel, F. and Andrès, E. (2007) Manifestations hématologiques de la carence en vitamine B12: Données personnelles et revue de la littérature. La Revue de Médecine Interne, 28, 225-223. https://doi.org/10.1016/j.revmed.2006.10.319

[4] Serraj, E.K., Mecili, M., Ciobanu, E., Vogel, T. and Weitten, T. (2009) Mise au point sur la vitamine B12 Andres administrée par voie orale. Annales d Endocrinologie, 70, 455-461. https://doi.org/10.1016/j.ando.2009.07.001

[5] Koulidiati, J., Sawadogo, S., Sagna, Y., Somda, K.S., Tieno, H., Kafando, E., et al. (2015) Pernicious Anemia: Diagnosis and Course in Burkina Faso. Medecine et Sante Tropicales, 25, 428-431. https://doi.org/10.1684/mst.2014.0417

[6] Ndiaye, F.S.D., Fall, S., Sarr, A., Laraki, S.D., Ka, M.M. and Diop, T.M. (2009) Données actuelles sur la maladie de Biermer. Hématologie, 15, 473-477. https://doi.org/10.1684/hma.2009.0394

[7] Amrani, R., Es-seddiki, A., Messaoudi, S. and Tazi, N. (2014) La maladie de biermer: Une entité rare en pédiatrie. Revue marocaine de santé publique, 1, 35-37.

[8] Wun Chan, J.C., Yu Liu, H.S., Sang Kho, B.C., Yin Sim, J.P., Hang Lau, T.K., Luk, Y.W., et al. (2006) Pernicious Anemia in Chinese: A Study of 181 Patients in a Hong Kong Hospital. Medicine (Baltimore), 85, 129-138. https://doi.org/10.1097/01.md.0000224710.47263.70

[9] Savage, D., Gangaidzo, I., Lindenbaum, J., Kiire, C., Mukiibi, J.M., Moyo, A., et al. (1994) Vitamin B12 Deficiency Is the Primary Cause of Megaloblastic Anaemia in Zimbabwe. British Journal of Haematology, 86, 844-850. https://doi.org/10.1111/j.1365-2141.1994.tb04840.x

[10] Agarwal, M.B. and Manocha, S. (2000) Acquired Hyperhomocysteinemia, Megaloblastosis with Subacute Combined Degeneration and Deep Venous Thrombosis. The Journal of the Association of Physicians of India, 48, 545-546.

[11] Diop, M.M. (2014) Maladie de biermer de cours inhabituel: A propos d'associations avec une beta-thalassemie et un syndrome de Plummer Vinson. Revue du CAMES: Science de la santé, 2, 45-48.

[12] Segbena, A.Y., Ambofo-Planche, Y., Gbadoe, A.D., Dogba, A.D., Kueviakoe, I.M., Vovor, A. and David, M. (2003) A propos de quatre observations de maladie de Biermer en Afrique de l'ouest. Medecinetropicale, 63, 593.

[13] Maktouf, C., Bchir, F., Louzir, H., Elloumi, M., Abid, H.B., Mdhaffer, M., et al. (2007) Le spectre clinique des déficits en cobalamines en Tunisie. Annales de biologie clinique (Paris), 1, 135-142.

[14] Btissame, E.-S. (2017) Anémie de Biermer : Polymorphisme clinique, caractéristiques épidémiologiques, thérapeutiques et évolutives, étude d'une série de 50 cas colligés au service de médecine interne de l'hôpital militaire de Moulay IsmaïlMeknes.

[15] Andrès, E., Affenberger, S., Vinzio, S., Noel, E., Kaltenbach, G. and Schlienger, J.-L. (2005) Carences en vitamine B12 chez l'adulte: Etiologies, manifestations cliniques et traitement. La Revue de Médecine Interne, 26, 938-946. https://doi.org/10.1016/j.revmed.2005.04.036

[16] Loukili, N.H., Noel, E., Blaison, G., Goichot, B., et al. (2004) Données actuelles sur la maladie de Biermer. À propos d'une étude rétrospective de 49 observations. La Revue de Médecine Interne, 25, 556-561. 
https://doi.org/10.1016/j.revmed.2004.03.008

[17] Annibale, B. (2005) Lack of Specific Association between Gastric Autoimmunity Hallmarks and Clinical Presentations of Atrophic Body Gastritis. World Journal of Gastroenterology, 11, 5351. https://doi.org/10.3748/wjg.v11.i34.5351

[18] Rufenacht, P., Iten, A. and Mach-Pascual, S. (2008) Hypovitaminose B12: Challenge diagnostique et thérapeutique. Revue Médicale Suisse, 4, 2212-2217.

[19] Eussen, S.J.P.M. (2005) Oral Cyanocobalamin Supplementation in Older People with Vitamin B12 Deficiency: A Dose-Finding Trial. Archives of Internal Medicine, 23, 1167. https://doi.org/10.1001/archinte.165.10.1167

[20] Kaltenbach, G., Andrès, E., Barnier-Figue, G., et al. (2005) Low Vitamin B12 Levels in Elderly Patients Cured within One Week by Oral Cobalamin Therapy. Presse Medicale, 34, 358-362.

[21] Drissi, J., Kassidi, F., Kouach, J., et al. (2015) Combined Degeneration of the Spinal Cord Diagnosed during Pregnancy: Report of a Case. International Journal of Innovation and Applied Studies, 12, 899.

[22] Loukili, N.H. and Andrès, E. (2003) Vitamine B12 chez l'adulte: Du métabolisme aux carences. Cour, 15, 30.

[23] Andrès, E., Renaux, V., Campos, F., et al. (2001) Troubles neurologiques isolés révélant une maladie de Biermer chez le sujet jeune. La Revue de Medecine Interne, 22, 389-393. https://doi.org/10.1016/S0248-8663(01)00352-6

[24] Ach, M.T., Akkari, I., Maaroufi, A., Kacem, M., Chaieb, M. and Ach, K. (2016) Anémie de Biermer et maladies auto-immunes: A propos de 28 cas. Annales d Endocrinologie, 77, 375. https://doi.org/10.1016/j.ando.2016.07.402 